\title{
Functional anatomy of non-REM sleep
}

\section{Isabel de Andrés, Miguel Garzón and Fernando Reinoso-Suárez *}

Departamento de Anatomía Histología y Neurociencia, Universidad Autónoma de Madrid, Instituto de Investigación Hospital Universitario La Paz, Madrid, Spain

\section{Edited by:}

Oscar Prospéro-García, Universidad Nacional Autónoma de México, Mexico

\section{Reviewed by:}

Matthew R. Ebben, Weill Medical College of Cornell University, USA Rene Druckner-Colin, Universidad Nacional Autonoma de Mexico,

Mexico

Javier Velazquez-Moctezuma,

Universidad Autonoma Metropolitana, Mexico

\section{*Correspondence:}

Fernando Reinoso-Suárez, Departamento de Anatomía Histología y Neurociencia, Universidad Autónoma de Madrid, Arzobispo Morcillo 4, Madrid 28029, Spain.

e-mail: fernando.reinoso@uam.es
The state of non-REM sleep (NREM), or slow wave sleep, is associated with a synchronized EEG pattern in which sleep spindles and/or K complexes and high-voltage slow wave activity (SWA) can be recorded over the entire cortical surface. In humans, NREM is subdivided into stages 2 and 3-4 (presently named N3) depending on the proportions of each of these polygraphic events. NREM is necessary for normal physical and intellectual performance and behavior. An overview of the brain structures involved in NREM generation shows that the thalamus and the cerebral cortex are absolutely necessary for the most significant bioelectric and behavioral events of NREM to be expressed; other structures like the basal forebrain, anterior hypothalamus, cerebellum, caudal brain stem, spinal cord and peripheral nerves contribute to NREM regulation and modulation. In NREM stage 2, sustained hyperpolarized membrane potential levels resulting from interaction between thalamic reticular and projection neurons gives rise to spindle oscillations in the membrane potential; the initiation and termination of individual spindle sequences depends on corticothalamic activities. Cortical and thalamic mechanisms are also involved in the generation of EEG delta SWA that appears in deep stage 3-4 (N3) NREM; the cortex has classically been considered to be the structure that generates this activity, but delta oscillations can also be generated in thalamocortical neurons. NREM is probably necessary to normalize synapses to a sustainable basal condition that can ensure cellular homeostasis. Sleep homeostasis depends not only on the duration of prior wakefulness but also on its intensity, and sleep need increases when wakefulness is associated with learning. NREM seems to ensure cell homeostasis by reducing the number of synaptic connections to a basic level; based on simple energy demands, cerebral energy economizing during NREM sleep is one of the prevalent hypotheses to explain NREM homeostasis.

Keywords: slow wave sleep, sleep need, thalamus-cerebral cortex unit, rostral hypnogenic system, caudal hypnogenic system, NREM sleep homeostasis

\section{INTRODUCTION}

The state of non-REM sleep (NREM), or slow wave sleep, is associated with a synchronized EEG pattern in which specific electrographic events take place. These events are sleep spindles and/or K complexes and high-voltage slow wave activity (SWA) within the delta frequency band (between 0.5 and $4.0 \mathrm{~Hz}$ ) that can be recorded over the entire cortical surface. In humans, NREM is subdivided into stages 2 and 3-4 depending on the proportions of each of these polygraphic events. Stage 2, with sleep spindles and $\mathrm{K}$ complexes and less than $20 \%$ of SWA in the recording, corresponds, from the behavioral point of view, to a light sleep with a low-threshold to awakening. Behaviorally, stage 3-4, with SWA occupying at least $20 \%$ of the recording, is a deeper sleep. Recently, in the new sleep scoring classification of the AASM (Iber et al., 2007) the former stage 3-4 is identified as only one stage, named N3. In young adults stage 3-4 (N3) is especially abundant in the first third of the night (Figure 1). Its proportions show notable stability in long and short sleepers, and it is the first stage to recover after sleep deprivation; it is considered to be the main component of the "core" sleep necessary for normal physical and intellectual performance and behavior. It usually decreases in the elderly.

\section{OVERVIEW OF THE BRAIN STRUCTURES INVOLVED IN NREM GENERATION}

Recently, in a revision of the publications describing the anatomical connections and effects of lesions and electrical stimulation of specific brain structures on the sleep-wakefulness cycle (SWC) we outlined the brain structures located at practically all levels of the encephalon that participate in the organization of the NREM state (Reinoso-Suárez et al., 2011; Figure 2). Also, different findings have shown that impulses from peripheral nerves and spinal cord can modify brain electrical activity increasing EEG synchronization and producing SWA, as occurs after stimulation of cutaneous nerves (Pompeiano and Swett, 1962), after repetitive visual stimuli or diffused and permanent illumination of the retina (Mancia et al., 1959), or after afferent volleys originating in the vagus nerve (Puizillout et al., 1973; Valdés-Cruz et al., 2008). Conversely, decrease of SWA in the EEG (and therefore enhancement of desynchronized EEG) takes place after suppression of trigeminal nerve afferents (Viñes-Morros, 1959), and after lesion or blockage of the spinal cord, thus indicating that ascending synchronizing impulses can also be generated in the spinal cord (Hodes, 1964; De Andrés et al., 1976). 
When the medulla and the caudal pons are separated from more cranially located brainstem structures, active and resting periods are still organized in a manner that can resemble very elemental waking and sleep states (Siegel et al., 1986). But, in the absence of influence from higher brainstem structures, the medulla, and caudal pons are unable to generate true NREM or REM sleep signs since the full expression of these states does not occur in chronic

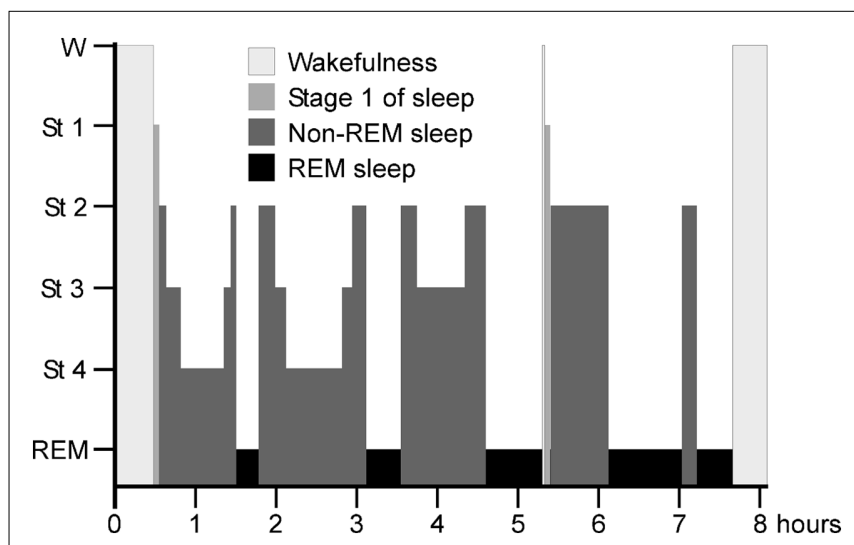

FIGURE 1 | Nocturnal hypnogram of a young man. Modified from Reinoso-Suárez et al. (2010). medullary or midpontine cats (Reinoso-Suárez et al., 2011). However, lesion and stimulation experiments in our and other laboratories demonstrated that EEG synchronizing hypnogenic influences on the rostral brainstem and prosencephalon originate in the caudal pons and medulla at the level of the nucleus of the solitary tract (Magnes et al., 1961; Berlucchi et al., 1964; Reinoso-Barbero and De Andrés, 1995) and caudal pontine reticular nucleus (Batini et al., 1958; Cordeau and Mancia, 1959; Reinoso-Suárez et al., 1962; Rossi et al., 1963; Camacho-Evangelista and Reinoso-Suárez, 1964; Zarranz and Reinoso-Suárez, 1971; Reinoso-Suárez and De Andrés, 1976; Garzón, 1996). These findings, together with the rostral projections of these lower brainstem structures (ReinosoSuárez et al., 1977), support the assertion by Moruzzi (1972) that the deactivating structures of the lower brainstem may inhibit the ascending reticular system and counteract its influence at the level of the diencephalon.

Our group reported that lesions in the long ascending tracts at the level of the oral pontine tegmentum produce EEG desynchronization; bilateral desynchronization of the EEG also followed uni- or bilateral lesions in the superior cerebellar peduncle that destroyed the brachium conjunctivum tract (CamachoEvangelista and Reinoso-Suárez, 1964, 1965). This led us to infer that these lesions suppressed ascendant hypnogenic synchronizing impulses from more caudal levels of the brainstem and the deep cerebellar nuclei. In the case of lesion to the brachium

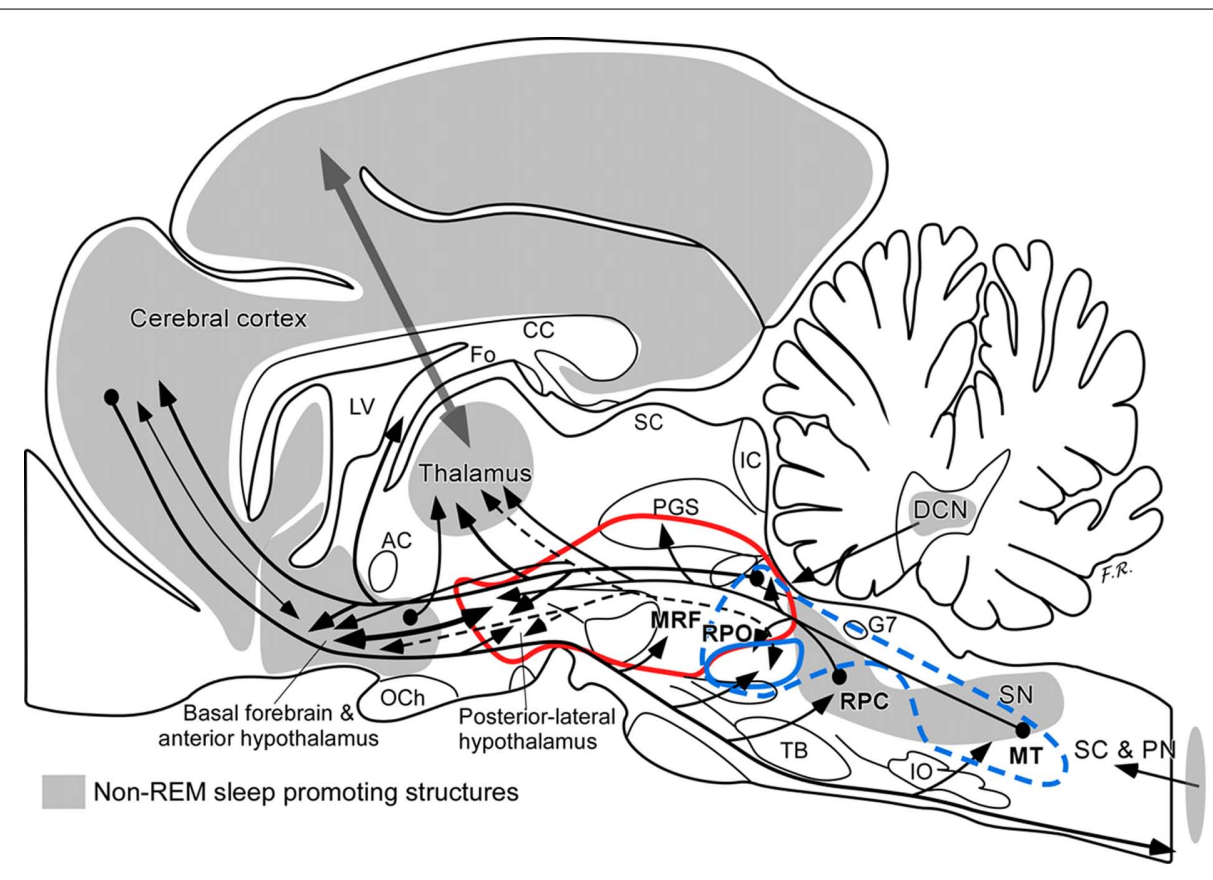

FIGURE 2 | Schematic representation of the encephalic NREM sleep-promoting structures. A parasagittal section of cat brain shows a shaded area representing the brain structures where lesion decreases NREM sleep and/or EEG synchronization or stimulation increases NREM sleep. The main connections between these structures and the structures responsible of the organization of wakefulness (encompassed in red line) or REM sleep (blue lines) - with the exception of the efferent hypothalamic and midbrain connections and the brainstem connections from the basal forebrain - are shown. The thalamus-cerebral cortex complex or unit is darker to emphasize that these structures are necessary for the behavioral and bioelectric signs that characterize NREM sleep. $\mathrm{AC}$, anterior commissure; $\mathrm{CC}$, corpus callosum; DCN, deep cerebellar nuclei; Fo, fornix; G7, genu of the facial nerve; IC, inferior colliculus; IO, inferior olive; LV, lateral ventricle; MRF; midbrain reticular formation; MT, medullary tegmentum; OCh, optic chiasm; PGS, periaqueductal gray substance; RPC, caudal pontine reticular nucleus; RPO, oral pontine reticular nucleus; SC, superior colliculus; SC and PN, spinal cord and peripheral nerves; SN, solitary nucleus; TB, trapezoid body. Modified from Reinoso-Suárez et al. (2011). 
conjunctivum tract, the suppression of the synchronizing impulses was associated to a bilateral increase of desynchronized EEG but also to the generation of bursts of intermediate- to high-voltage theta band EEG activity recorded in cortical areas (motor and parietal cortices) that are targets of the thalamic nuclei where cerebellar projections end (Camacho-Evangelista and Reinoso-Suárez, 1965; Reinoso-Suárez, 1992, 1993). In agreement with these results, unilateral lesions of the brachium conjunctivum in cats increased wakefulness and drowsiness while decreasing NREM and REM sleep (De Andrés and Reinoso-Suárez, 1979).

Sleep spindles and delta SWA cannot be observed in decerebrate animals in which the brainstem has been released from prosencephalic influences (Villablanca, 1966; De Andrés and Corpas, 1991), even though, these preparations show the behavioral and bioelectric REM sleep signs. On the other hand, the isolated forebrain (or cerveau isolé preparation) of cats transected at the intercollicular level, which lacks brainstem influences, is able to express the full bioelectric activity patterns of NREM sleep (Villablanca, 1965; Corpas and De Andrés, 1991). In addition, when the third cranial nerves and nuclei are not affected by the transection in the cerveau isolé preparation, the bioelectric EEG activities in the isolated forebrain are coupled to pupil size changes, that is, myosis during synchronized EEG and mydriasis during desynchronized EEG, that occur in intact cats during NREM sleep and wakefulness, respectively (Villablanca, 2004). Furthermore, prosencephalic mechanisms are sufficient for homeostatic regulation of NREM sleep: pharmacologic deprivation of this state in the cerveau isole preparation is followed as in intact animals by an NREM sleep rebound (Corpas and De Andrés, 1991).

In addition, clinical, and lesion and stimulation experiments made it possible to describe a rostral NREM hypnogenic system that includes the basal forebrain, and preoptic and anterior hypothalamic regions (von Economo, 1930; Hess, 1931; Nauta, 1946; Hernández-Peón, 1962; Sterman and Clemente, 1962; Madoz and Reinoso-Suárez, 1968; McGinty and Sterman, 1968; Szymusiak and McGinty, 1986). The ventral lateral preoptic area and the median preoptic nucleus show a higher density of neurons with increased activity during NREM episodes than do other anterior hypothalamic regions (Szymusiak et al., 1998).

Also, lesion, stimulation, and clinical studies demonstrate that the thalamus is necessary to generate the electrophysiological and behavioral manifestations that characterize NREM sleep (Hess, 1931, 1968; Morrison and Dempsey, 1942; Villablanca, 1974; Steriade et al., 1985; Sforza et al., 1995). The chronic athalamic cat shows wakefulness and REM sleep but not typical NREM sleep (Villablanca, 2004). Also Villablanca $(1972,2004)$ affirmed that true NREM sleep is absent in chronic cats without telencephalon (diencephalic cats) because neither delta SWA nor sleep spindles could be recorded in the thalamus.

In summary, it appears that the thalamus and the cerebral cortex are absolutely necessary for the expression of the most significant bioelectric and behavioral events of NREM sleep. Other structures like the basal forebrain, cerebellum and caudal brain stem, and impulses from the spinal cord and peripheral nerves modulate NREM sleep but are not required for the actual generation of the bioelectric and behavioral signs accompanying the expression of NREM sleep (Figure 2).

\section{THE THALAMUS AND THE CEREBRAL CORTEX}

The thalamus and the cerebral cortex work as an indivisible unit in brain functions. The cerebral cortex is the main afferent and efferent structure for the thalamus, and, in turn, the thalamus is the main subcortical afferent and efferent structure for the cerebral cortex (Reinoso-Suárez et al., 2011; Figures 3 and 4). In both cases these connections are made of two types of projection neurons (Jones, 2001; Rubio-Garrido et al., 2009; Figures 3 and 4): the thalamus sends projections from core- $(\mathrm{C})$ and matrix- $(\mathrm{M})$ type thalamocortical neurons and the cerebral cortex sends projections from layer VI and layer $\mathrm{V}$ neurons.

The axons of both types ( $\mathrm{M}$ and $\mathrm{C}$ ) of thalamocortical projection neurons provide collateral branches to the thalamic reticular nucleus when traversing it on their way to the cerebral cortex. The GABAergic thalamic reticular neurons that receive these collaterals project back, modulating both the thalamic projection neurons that provide the thalamocortical axons as well as the related interneurons (Figure 3). Thalamic innervation in cortical

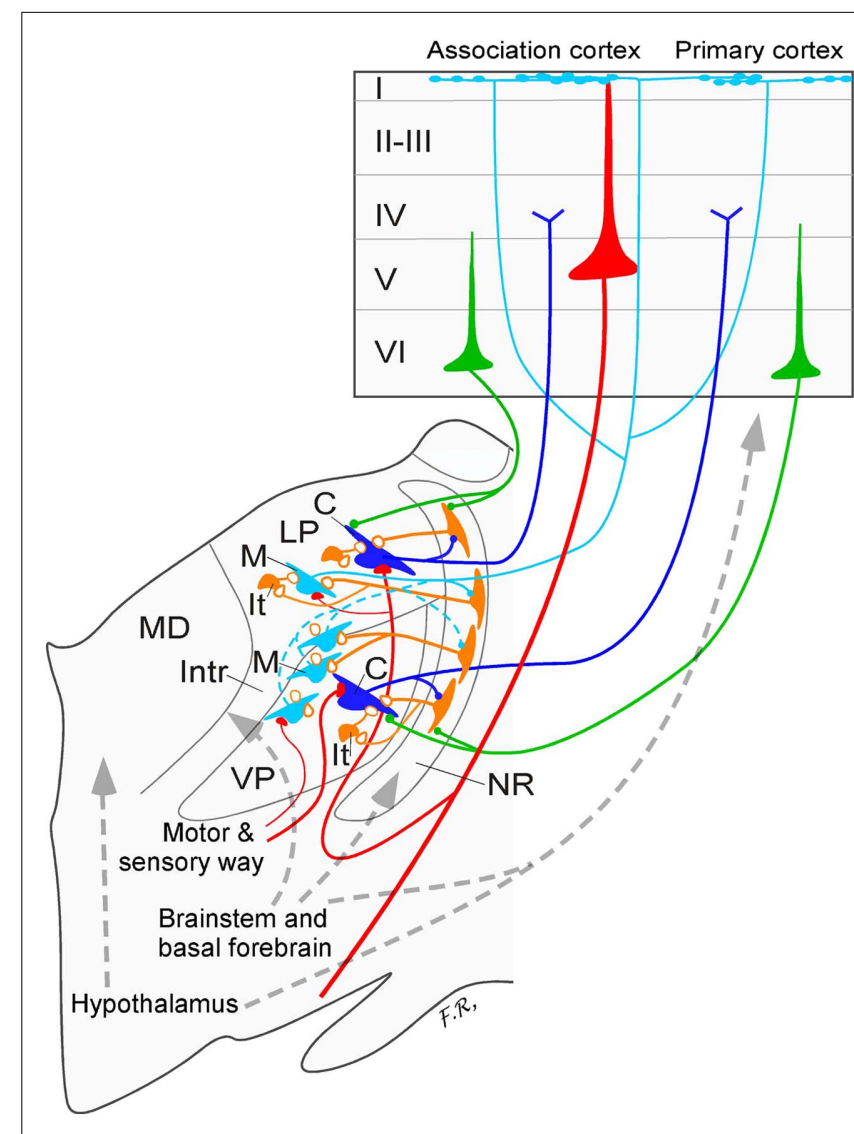

FIGURE 3 |Thalamic nuclei, cell types, and thalamocortical relationships. The lower part of the figure represents a schematic coronal section of the primate diencephalon and the upper drawing depicts a schematic section of the primary and association cerebral cortices. Thalamic lateral posterior (LP) and ventral posterior (VP) nuclei are represented as examples of high-order and first-order thalamic nuclei, respectively. $\mathrm{C}$, core-type cells; Intr, thalamic intralaminar nuclei; It, GABAergic interneurons; $M$, matrix-type cells; $M D$, medial dorsal thalamic nucleus; NR, thalamic reticular nucleus; I-VI, cortical layers. Modified from Reinoso-Suárez et al. (2011). 


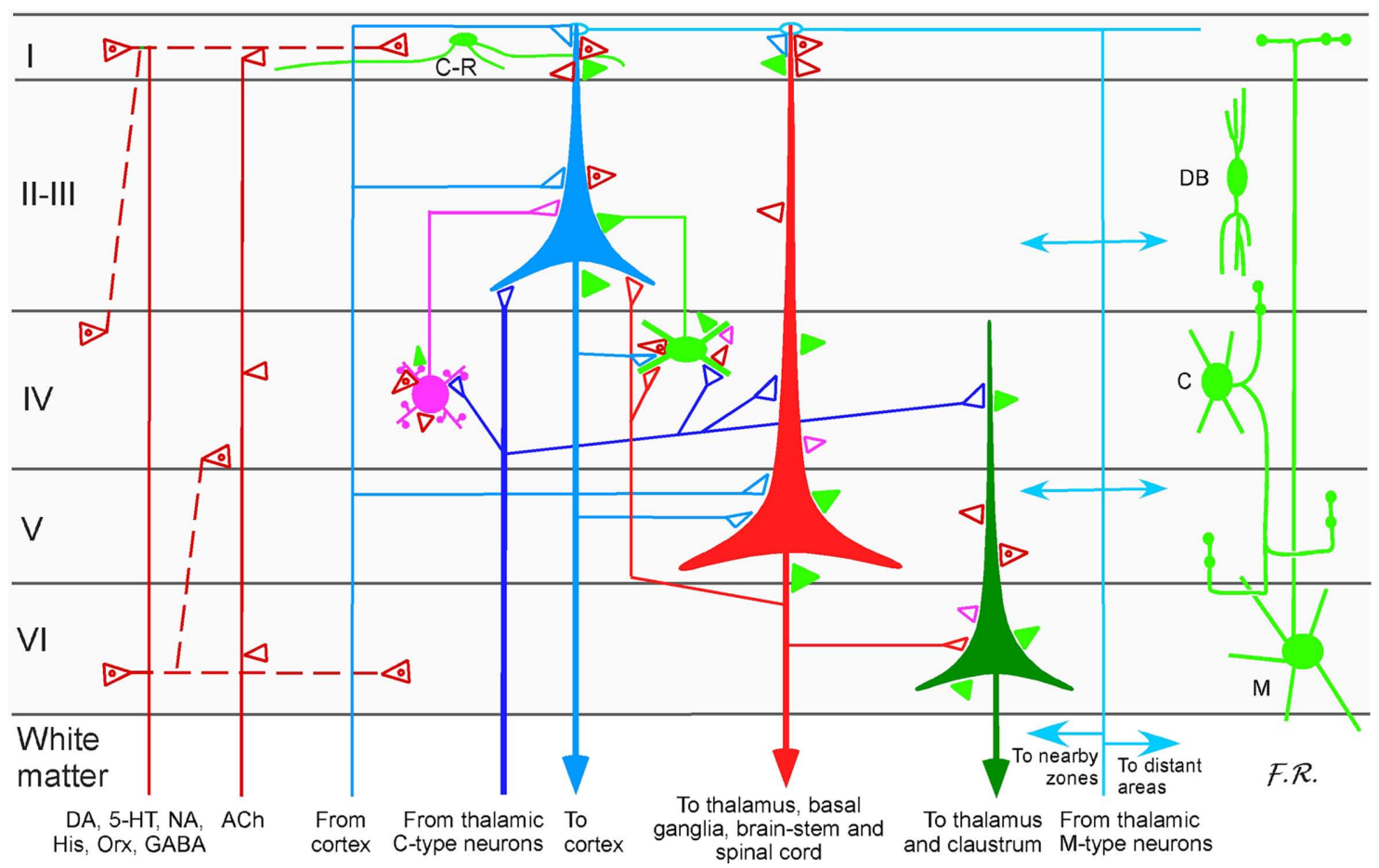

FIGURE 4 | Schematic representation of the fiber and neuronal organization of the cerebral cortex. The projection neurons, pyramidal neurons in layers II-III, V, and $\mathrm{VI}$, are represented in different colors according to their origin and targets. The two types of interneurons are represented in different colors: (1) the excitatory interneuron, a spiny stellate cell, is in pink; and (2) the inhibitory interneurons are in light green. There are four specific examples of inhibitory interneuron: two dendrite-and tuft-targeting cells [Cajal-Retzius (C-R) and Martinotti (M) neurons], one dendrite targeting cell [double bouquet (DB) neuron], and one axon targeting cell [chandelier (C) neuron]. Afferent fibers from cortical and subcortical origins are represented in different colors and specific distributions. The wide distributions of dopaminergic (DA), serotonergic (5-HT), noradrenergic (NA), histaminergic (His), orexinergic (Orx), and GABAergic (GABA) fibers originating in brainstem, diencephalic, and basal prosencephalic structures are represented by their terminals, as is the topographically organized terminals of the basal forebrain cholinergic (Ach) fibers. Thalamocortical fibers targeting cortical layers I (M-type) and IV (C-type) are also shown. I to VI, cortical layers one to six. Open triangles, excitatory terminals; solid triangles, inhibitory terminals. From Reinoso-Suárez et al. (2011). layer I is at least as heavy as that in layer IV; every part of cortical layer I receives combined input from multiple thalamic nuclei (Rubio-Garrido et al., 2009).

Since the 1980s, the thalamocortical and corticothalamic cellular bases of sleep spindles and delta SWA generation have been extensively studied by Steriade et al. (1985, 1988, 1991, 1993). In a series of experiments these authors showed that the combination of the intrinsic electrophysiological properties of the thalamic and cortical neurons, together with their synaptic connections, is responsible for the generation of sleep spindles and delta SWA oscillations in the EEG during NREM sleep (for review see NúñezMolina and Amzica, 2004; Fuentealba and Steriade, 2005). Thus, the EEG activities, which appear during stages 2 and 3-4 (N3) of NREM sleep are essentially generated by the activity of neurons in the thalamic reticular nucleus, in the thalamocortical projecting nuclei, and in the cerebral cortex.

Steriade et al. (1985) proposed, early on, that the neurons of the thalamic reticular nucleus are pacemakers for sleep spindles, based on the absence of the sleep spindle oscillation in thalamocortical systems when they are disconnected from the thalamic reticular nucleus and the presence of spindle rhythmicity in the deafferentized reticular thalamic nucleus. Bal and McCormick (1993) demonstrated that reticular nucleus neurons have an intrinsic rhythmic activity at spindle frequencies $(7-12 \mathrm{~Hz})$ in slice preparations. The thalamic reticular nucleus is a relatively thin sheet of neurons that surrounds the anterior, lateral and, to some extent, ventral surfaces of the dorsal thalamus, and it is entirely composed of GABAergic cells. Because of its anatomical position the thalamic reticular nucleus is traversed by virtually all axons connecting the dorsal thalamus with the neocortex, giving the nucleus its reticulated appearance and name; it also receives collateral branches from corticothalamic fibers originating in cortical layer VI (Figures 3 and 5). Thalamic reticular nucleus neurons do not project directly to the cortex although they widely project to the relay thalamic nuclei. Simultaneous intracellular recordings in reticular, thalamocortical, and cortical neurons (Steriade and Deschenes, 1988) indicated that sleep spindle generation was produced by a chain of events with three main consecutive steps: (1) repetitive spike-bursts at spindle frequency generated by GABAergic thalamic reticular nucleus neurons; (2) transfer of this activity to relay thalamocortical nuclei producing rhythmic (at spindle frequency) inhibitory postsynaptic potentials 


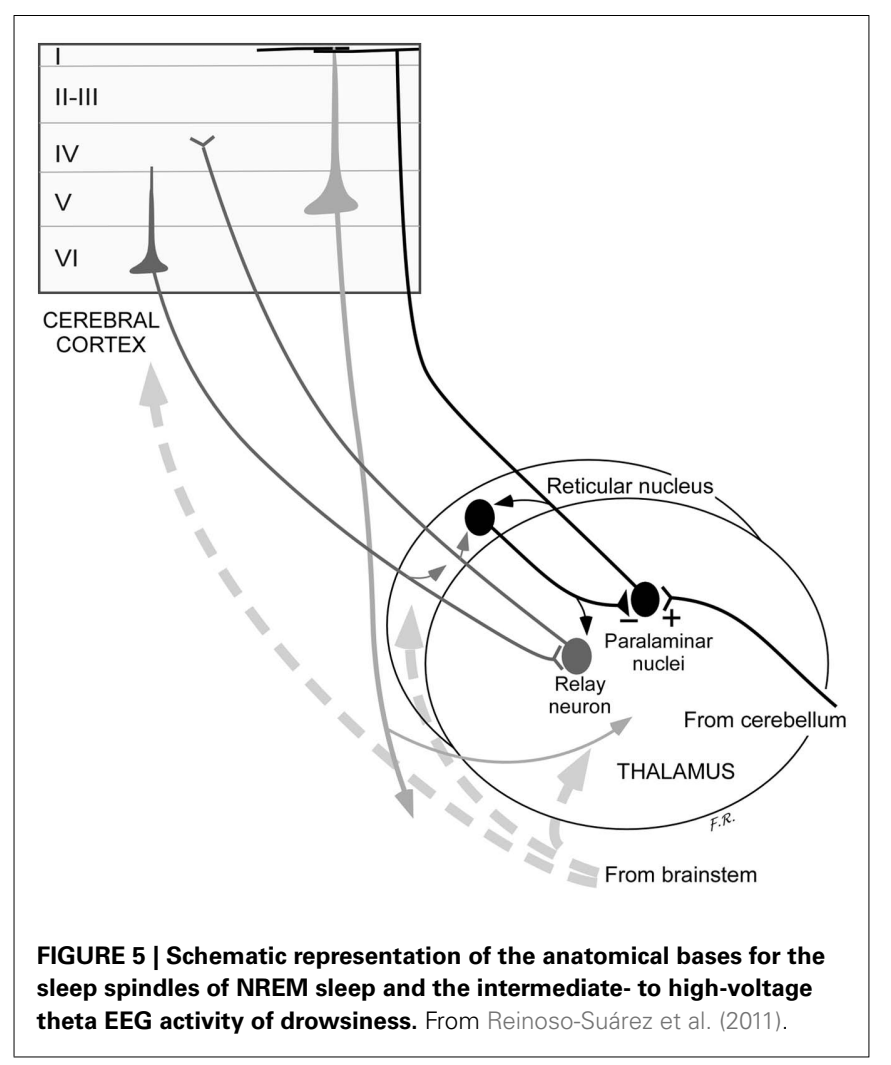

(IPSPs) in thalamocortical neurons; and (3) transfer to the cerebral cortex of postinhibitory rebound spike-bursts of the thalamocortical cells producing excitatory postsynaptic potentials (EPSPs) in cortical cells at spindle frequency. The repetitive spike-bursts of the reticular nucleus neurons are $\mathrm{Na}^{+}$action potentials generated by low-threshold $\mathrm{Ca}^{+}$spikes at spindle frequency (Bal and McCormick, 1993). Since the reticular nucleus projection is GABAergic, the reticular nucleus activities are transmitted to the thalamocortical relay nuclei generating rhythmic IPSPs in these cells. Thalamocortical relay cells are able to generate $\mathrm{Ca}^{+}$spikes at membrane hyperpolarizing levels (Jahnsen and Llinás, 1984), these $\mathrm{Ca}^{2+}$ spike makes it possible to generate $\mathrm{Na}^{+}$potentials in the re-polarizing phase of the IPSPs that can reach the cerebral cortex and produce rhythmic EPSPs in cortical neurons at the sleep spindle frequencies (Steriade and Deschenes, 1988) since the thalamic afferents to the cerebral cortex are glutamatergic (Figures 3 and 5). Finally, in relation with the cellular basis of the sleep spindles, it is noteworthy that spindle oscillations in the membrane potential of the reticular and thalamocortical neurons arise from sustained hyperpolarized membrane potential levels (Llinás and Steriade, 2006), and that thalamocortical or corticothalamic collaterals to the thalamic reticular nucleus can reinforce the generation of sleep spindles. Synaptic activation of the thalamic reticular nucleus neurons by stimulation of these afferents invariably determines the generation of a sequence of spindle waves crowned with spike-bursts.

The recruiting responses are the neurophysiological activity that can be experimentally elicited in the cat cortex after lowfrequency stimulation of the intralaminar and related nuclei
(Morrison and Dempsey, 1942); these responses resemble the EEG activity recorded in superficial layer I of the cortex during sleep spindles (Hess, 1968). The frontal and posterior parietal cortices are the cortical regions that are the prime location for recruiting responses and spontaneous spindling in the cat (Morrison and Dempsey, 1942; Starzl and Magoun, 1951; Reinoso-Suárez, 1954). The superficial thalamocortical projection system to layer I in the frontal and posterior parietal cortex of the cat does not arise from intralaminar nuclei but from the paralaminar region of ventral medial, ventral anterior, and ventral lateral nuclei (Oka et al., 1982; Avendaño et al., 1990). In addition, the M-type cells of these nuclei innervate wider zones of layer I of the cerebral hemisphere, as it also happens in rats (Rubio-Garrido et al., 2009). Consequently this layer I projection system to the frontal and posterior parietal cortices may be an important leading path for recruiting responses and spontaneous spindling activities (Oka et al., 1982; Avendaño et al., 1990). In relation with the possible thalamocortical route for sleep spindle generation, Jiménez-Castellanos and Reinoso-Suárez (1985), Velayos et al. (1989), and Avendaño et al. (1990) proposed a circuit that involves the thalamic reticular nucleus and its projection to the paralaminar ventral medial, ventral anterior, and ventral lateral nuclei (Figure 5). The thalamic reticular nucleus GABAergic pacemaker neurons of the spindle oscillations would impose their rhythmicity on the paralaminar M-type neurons that project to layer I of the frontal and parietal cortices (Reinoso-Suárez et al., 2011; Figures 3 and 5). For this to occur, as happens in stage 2 of NREM sleep, it is necessary to decrease the brainstem activating system action on both the thalamic reticular nucleus neurons, which consequently fire at their intrinsic burst activity, and the paralaminar neurons, which then transfer the slow burst activity to the cortex. Altogether this permits the thalamic paralaminar M-type neurons projecting to layer I of the cerebral cortex, in their turn, impose this activity on the cortex, which has also been released from the influence of the ascending activating system (Figure 5; Reinoso-Suárez, 1992, 1993; Reinoso-Suárez et al., 2011). Recently Bonjean et al. (2011) have concluded that spindle oscillation initiation depends on activity by cortical pyramidal neurons on thalamic reticular nucleus neurons, which would then fire synchronizing discharges. The intermediate phase would be the interaction of thalamic reticular nucleus neurons with the thalamic projection neurons as we have described above. Spindle firing is terminated by the combination of $I_{\mathrm{h}}$ current and corticothalamic input depolarizing actions. Consequently corticothalamic activity is involved not only in the long-range synchronization of spindles but also in the initiation and termination of individual spindle sequences, and this controls spindle duration.

Andrade et al. (2011) have investigated human hippocampal functional connectivity with neocortex in wakefulness and during NREM sleep. They found that the strongest functional connectivity between the hippocampal formation and neocortex was observed in stage 2 sleep spindles. The hippocampal structure dominating functional connectivity to frontal neocortex regions during sleep stage 2 was the subiculum. This increased connectivity between the hippocampal formation and neocortical regions suggests an increased capacity for possibly global information transfer in sleep stage 2 and would support the hypothesis of sleep-dependent memory consolidation. 
Cortical and thalamic mechanisms are also involved in the generation of EEG delta SWA that appear in deep NREM sleep stage 3-4. EEG with SWA can be registered in the cortex of cats without thalamus (Villablanca, 1974); therefore, the cortex has classically been considered to be the structure that generates this activity. However, Steriade et al. (1991, 1993) showed that delta oscillations can also be generated in thalamocortical neurons. These cells express this property intrinsically when their membrane potential is at more strongly hyperpolarized levels than during sleep spindles. In thalamic cells, delta is an intrinsic oscillation consisting of low-threshold spikes alternating with post-hyperpolarizing potentials. Action potentials at delta frequency that can be transferred to the cortex are generated in the depolarizing phase of the $\mathrm{Ca}^{2+}$ lowthreshold spikes. Therefore, there is a degree of incompatibility in simultaneously generating thalamic spindles and delta rhythms; this may explain the distinct prevalences of these two types of oscillations during the different stages of NREM [stages 2 and 3-4 (N3) respectively] with synchronization of the electroencephalogram (Nuñez et al., 1992).

In fact, the thalamus and the cerebral cortex are close structures and abundantly interconnected, and they form a non-divisible unit in brain functions. During NREM sleep oscillating cortical activities can be transferred to specific thalamic structures via cortical efferents from layer VI and V pyramidal neurons; in turn, thalamic oscillating activities can reach cortical neurons principally through M-type, but also C-type, thalamocortical neurons, since the former innervate extensive zones of layer I of the cerebral cortex and can convey oscillatory information activity to the distal apical tufts of pyramidal neurons from layers II, III, and V, neurons which are source for corticocortical and subcortical connections.

The different oscillatory activities and spike-bursting mode in thalamic and cortical neurons that we have just described are completely absent in wakefulness and/or REM where the associated EEG is desynchronized. During the later states, thalamic and cortical neurons are depolarized and show a tonic firing discharge pattern (Llinás and Steriade, 2006). The level of the membrane potential of thalamic neurons is mainly controlled by cholinergic input and, in wakefulness by additional glutamatergic and aminergic inputs, from the mesopontine cholinergic, glutamatergic, and aminergic cell groups. Stimulation of cholinergic mesopontine nuclei produces an opposite effect in thalamic cells to the effects of corticothalamic volleys, readily suppressing their slow oscillatory bursts due to the generation of excitatory depolarizing discharges that produce a tonic firing pattern of activity in thalamic neurons (Steriade et al., 1991). The firing rate of the cholinergic laterodorsal and pedunculopontine mesopontine nuclei neurons is increased during wakefulness and REM sleep in comparison with firing rate during NREM sleep (Steriade et al., 1982); therefore, when the activity of the cholinergic mesopontine, hypothalamic and basal forebrain, and glutamatergic and aminergic mesopontine structures decreases during NREM, the membrane potential of thalamic and cortical cells is hyperpolarized. This allows the generation of oscillatory patterns in the thalamic and cortical neurons, leading to expression of the specific EEG events of the NREM stages (Steriade and McCarley, 1990).

Finally, intracellular recording experiments of cortical and thalamic neurons during synchronized EEG states detected that delta membrane oscillations were accompanied by a slower $<1 \mathrm{~Hz}$ membrane rhythm (Dossi et al., 1992). This oscillation consists of a depolarized (UP) state in which neurons fire followed by a hyperpolarized (DOWN) state with neuronal silence. There is a close temporal relationship between the $>1 \mathrm{~Hz}$ cellular oscillation and the 1 - to $4-\mathrm{Hz}$ delta EEG waves since the negative component of the EEG signal corresponds to the DOWN state of the cortical neurons (Contreras and Steriade, 1995). The cortical origin of these slow $<1 \mathrm{~Hz}$ rhythm waves was demonstrated by the presence of the oscillation in the cerebral cortex after thalamectomy (Steriade et al., 1993) and its absence in the thalamus of decorticated animals (Timofeev and Steriade, 1996). The cortical slow $<1 \mathrm{~Hz}$ activity is expressed synchronously in wide areas of the cerebral cortex; disconnection of intracortical synaptic linkages does not abolish the $<1 \mathrm{~Hz}$ activity, but it does determine the loss of its synchronization between the different cortical areas (Amzica and Steriade, 1995). These findings indicate a possible role for $<1 \mathrm{~Hz}$ cortical activity in synchronous excitation of wide brain territories (cortical and thalamic) during NREM, which would allow the simultaneous expression of the same EEG activities in all territories (Núñez-Molina and Amzica, 2004). Interestingly, the generation of K complexes during stage 2 of NREM sleep seems to be related with the $<1 \mathrm{~Hz}$ rhythm of the cortical pyramidal cells as the $\mathrm{K}$ complexes can be generated by stimulation of a cortical area other than the one in which they are recorded. Also, K complexes can be evoked by sensory stimuli arriving at the cerebral cortex (NúñezMolina and Amzica, 2004). K complexes, during NREM stage 2, are usually followed by a sleep spindle; in these circumstances, it is possible that the $<1 \mathrm{~Hz}$ cortical activity would be sufficient to induce thalamic reticular nucleus neuron oscillation at the sleep spindle frequencies, since, as we have indicated above, stimulation of corticothalamic afferents to the reticular nucleus is one the most efficient stimuli in evoking rhythmic activity in reticular thalamic cells at sleep spindle frequencies.

\section{BASAL FOREBRAIN ANTERIOR HYPOTHALAMIC STRUCTURES}

Beside thalamus and cerebral cortex, the preoptic region and the anterior hypothalamus are other prosencephalic regions involved in NREM mechanisms (Figure 2). As we have mentioned before, von Economo (1930) was the first to suggest that the anterior hypothalamus was a sleep-promoting structure (Reinoso-Suárez et al., 2011); later on in the sixties, the importance of this region in the mechanisms for NREM generation was confirmed after behavioral sleep associated with synchronized EEG was obtained with electrical stimulation of the preoptic region and of the basal forebrain (Sterman and Clemente, 1962) and by the insomnia that followed electrolytic or diathermocoagulation lesions in these areas (Madoz and Reinoso-Suárez, 1968; McGinty and Sterman, 1968). Also, selective neurotoxic lesions of the preoptic neurons induce insomnia (Szymusiak and McGinty, 1986) thus indicating that the loss of local neurons rather than of fibers of passage is critical for sleep control. Single unit recordings have shown that the preoptic region as well as the basal forebrain there hold neurons whose discharge rate is higher during NREM than in W; in addition, many preoptic- and diagonal band-sleep active neurons are also heat-sensitive (Alam et al., 1995). The same local thermal 
stimuli that activate preoptic heat-sensitive neurons produce a sleep propensity and NREM with delta SWA (see Szymusiak et al., 2007 for a review of the close interactions between sleep regulation and thermoregulation together with the numerous factors that modulate the activity of the sleep-sensitive neurons in the anterior hypothalamus). Clusters of neurons exhibiting sleep-related c-Fos protein immunostaining were found in the ventral lateral preoptic area and in the median preoptic nucleus (Sherin et al., 1996). Neuronal density with increased activity during NREM episodes is higher in these regions than in other anterior hypothalamic sites (Szymusiak et al., 1998). Neurons of the ventral lateral preoptic area contain the inhibitory neuromodulator galanin and the inhibitory neurotransmitter GABA (Sherin et al., 1998); GABA is also found in most cells in the median preoptic nucleus (Gong et al., 2004). Anatomical tracer studies have shown that the ventral lateral preoptic area and the median preoptic nucleus project to arousal-related regions in the posterior hypothalamus and midbrain including the histaminergic tuberomammillary nucleus (Sherin et al., 1998), the hypocretinergic/orexinergic perifornical hypothalamic area (Uschakov et al., 2006; Yoshida et al., 2006), the serotonergic dorsal raphe, and the noradrenergic locus coeruleus (Steininger et al., 2001). All of these findings indicate that the preoptic area may promote sleep onset and maintenance by producing an inhibitory modulation of multiple arousal systems (Szymusiak et al., 2007). In fact, GABA-mediated inhibitory actions in histaminergic tuberomammillary neurons were demonstrated after electrical stimulation of the ventral lateral preoptic area (Yang and Hatton, 1997). Also, local warming of the preoptic region (a stimulus that - as we have mentioned before - activates preoptic warmth-sensitive neurons and generates NREM) causes suppression of waking related firing in both dorsal presumedly serotonergic raphe nucleus neurons (Guzmán-Marín et al., 2000) and in hypothalamic perifornical neurons (Krilowicz et al., 1994). Recently, it has been demonstrated that sleep-regulatory molecules like interleukin-1, tumor necrosis factor, and growth hormonereleasing hormone, stimulate NREM sleep by acting on neurons in the preoptic region. In addition, NREM sleep-promoting actions also take place through interleukin-1 and tumor necrosis factor inhibitory actions on locus coeruleus neurons and by interleukin1 action on serotonergic raphe cells. What is more, the facilitation of NREM sleep can occur when the lateral hypothalamic perifornical area is subject to a endogenous adenosinergic inhibition that restrains the wakefulness-generating hypocretinergic/orexinergic neurons (Krueger et al., 2008; Rai et al., 2010).

Anatomical studies have demonstrated that most of the posterior hypothalamic- and monoaminergic- arousal systems send feedback projections to the ventral lateral preoptic area (Chou et al., 2002; Reinoso-Suárez et al., 2011). In vitro experiments have indicated that the wake-promoting neurotransmitters serotonin, noradrenalin, and acetylcholine inhibit identified preoptic GABA neurons (Gallopin et al., 2000); therefore, mutually inhibitory interactions between the sleep-promoting preoptic region and the arousal-related hypothalamic and midbrain structures may provide a substrate for a "sleep-wakefulness switch" (McGinty and Szymusiak, 2000; Saper et al., 2001). Thus, activation of preoptic sleep-promoting cells could lead to sleep onset by inhibiting arousal structures; in turn, activation of arousal hypothalamic and midbrain structures could suppress activity by preoptic NREM sleep-promoting cells as well as REM-promoting neurons (Reinoso-Suárez et al., 2010) and facilitate the switch to wakefulness. Finally, the involvement of the preoptic region in homeostatic sleep regulation has been reported in recent experiments examining the patterns of c-Fos immunoreactivity in preoptic neurons following acute total sleep deprivation or selective REM sleep restriction (Gvilia et al., 2006a,b). These studies indicate that the GABAergic ventral lateral preoptic neurons are more strongly activated in response to increasing sleep amounts during sleep rebound, whereas GABAergic cells of the median preoptic nucleus are more strongly activated in response to sleep pressure during sleep deprivation. Thus, within the prosencephalon, the preoptic region seems to be deeply involved in homeostatic NREM and REM sleep mechanisms. Prosencephalic mechanisms underlying sleep homeostasis have been indicated by the capacity of the isolated forebrain to present NREM sleep rebound after pharmacological deprivation (Corpas and De Andrés, 1991) and the absence of REM rebound in REM sleep-deprived decerebrate animals (De Andrés and Corpas, 1991; De Andrés et al., 2003).

\section{BRAINSTEM AND CEREBELLAR STRUCTURES}

As we have mentioned in the introduction, early work with brainstem transections or lesions below the oral pontine tegmentum indicated that sleep-generating structures were located in the lower brainstem. NREM with EEG synchronization could be obtained in behaving cats by low-frequency electrical stimulation of the medullary reticular formation at the level of the solitary tract nucleus (Magnes et al., 1961), but lesion and stimulation studies in the peripheral nerves, spinal cord, caudal pontine tegmentum, and deep cerebellar nuclei can also induce hypnogenic synchronizing impulses (Figure 2).

The solitary tract nucleus region in the dorsal medulla is thought to provide a link between visceral activities such as respiratory, cardiovascular and gastrointestinal functions, and the sleep-wakefulness states. Biochemically, the solitary tract nucleus is a rather heterogeneous region where most viscerosensory afferent fibers from the VIIth, IXth, and Xth cranial nerves terminate; therefore, this region has important roles in the central regulation of visceral functions, but it also influences sleep-wakefulness states and electrical activity of the cerebral cortex. Not only does electrical stimulation of the solitary tract nucleus result in behavioral sleep with slow-EEG waves, these responses have also been obtained after the local administration of a variety of substances including serotonin (Laguzzi et al., 1984), morphine and other opiates agonists of mu or delta opioid receptors (Reinoso-Barbero and De Andrés, 1995; Figure 6), and glutamate (Golanov and Reis, 2001). These latter findings indicate that it is the activation of intrinsic solitary tract nucleus neurons and not of passing fibers that is responsible for the sleep and EEG responses. Unit activity studies have shown that there is a population of neurons in the solitary tract nucleus with an increased firing rate during NREM sleep (Eguchi and Satoh, 1980). The solitary tract nucleus does not directly project to the cerebral cortex (Saper, 1995), although it does project to several brainstem, thalamic, and hypothalamic areas that innervate the cortex and can mediate EEG and sleep responses. These areas include: locus coeruleus, raphe 


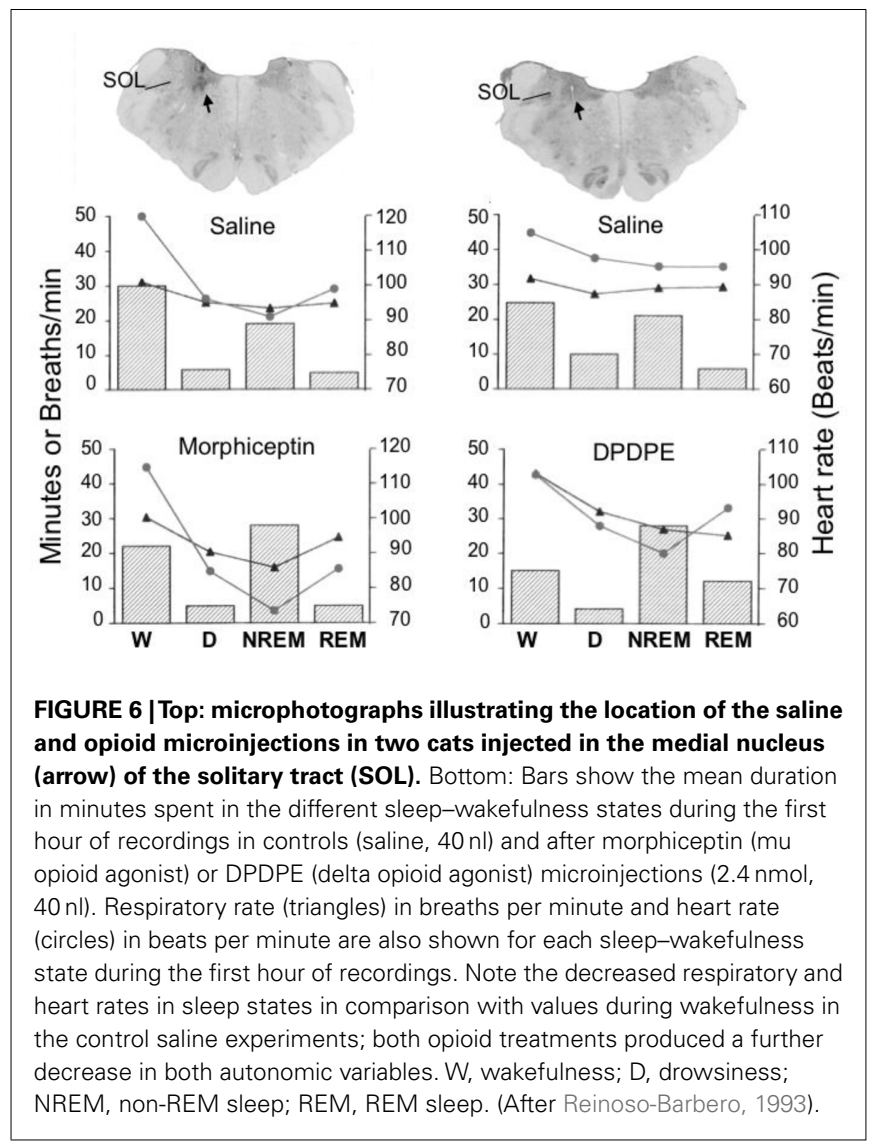

and parabrachial nuclei, lateral hypothalamus, and nuclei of the midline thalamus.

Results from our group's early work with lesions showed the existence of ascending EEG synchronizing influences arising from the rostral and intermediate parts of the nucleus reticularis pontis caudalis. Lesions in these areas decreased SWA in the cerebral cortex and the bioelectrical and behavioral signals of NREM and REM sleep (Figure 7; Camacho-Evangelista and ReinosoSuárez, 1964; Zarranz and Reinoso-Suárez, 1971; Reinoso-Suárez and De Andrés, 1976). More recent experiments microinjecting small amounts of a carbachol solution in rostral and intermediate parts of the nucleus reticularis pontis caudalis produced a synchronized EEG pattern associated with some REM sleep signs such as isolated and/or clustered PGO waves; the most rostral microinjections were also associated with muscular atonia (Garzón, 1996; Reinoso-Suárez et al., 2001). Power spectra analyses indicated that the synchronized EEG pattern obtained in these experiments did not consist of delta waves, instead, the high-voltage SWA activity was produced by enhancement of theta and alpha band frequencies (Garzón, 1996). Therefore, this cortical electrical pattern does not correspond to fully developed NREM sleep; instead, these electrical features are more similar to those expressed in the EEG during the transitional period between NREM and REM sleep (Gottesmann, 1996). Recently we have reported (Moreno-Balandrán et al., 2008) that low-doses and small carbachol microinjections delivered in the dorsal part of the oral pontine tegmentum in cats, at the level of the perilocus coeruleus alpha, produce a similar

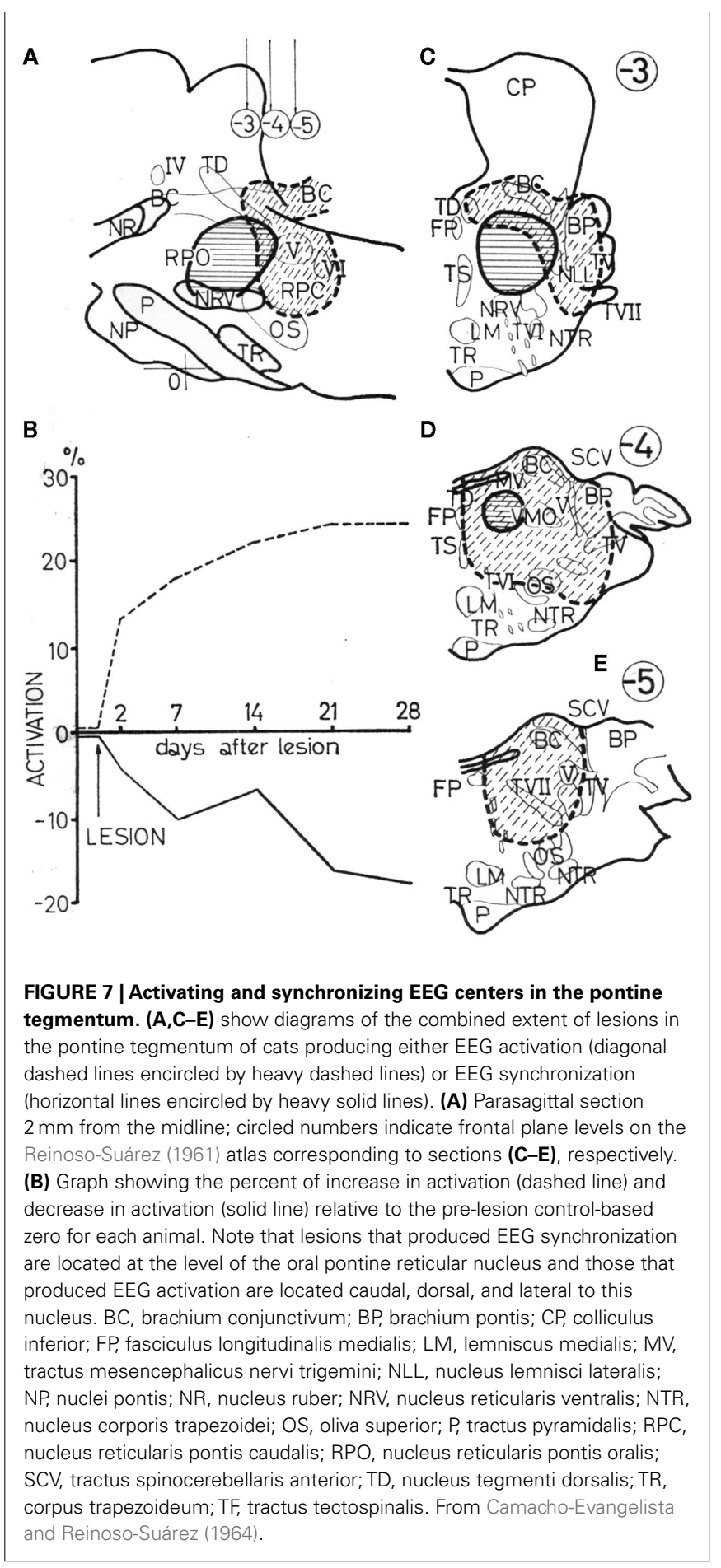

synchronized EEG without delta wave enhancement. These results indicate that not only is the pontine tegmentum the neural substrate for REM sleep and desynchronized EEG mechanisms, but that its caudal region - especially the rostral and intermediate areas of the nucleus reticularis pontis caudalis; together with the dorsal part of the oral region - seems to be involved in generating the pattern of bioelectrical activity that announces REM onset from NREM sleep. 
The major role of the cerebellum in motor functions has undervalued its possible involvement in sleep regulation. Cerebellar participation in sleep can be related to motor activities during sleep but also to intrinsic sleep mechanisms. The former activities involve postural adjustment and control of muscle tone and movements during sleep that, as in wakefulness, must be controlled by the cerebellum; in fact, early experimental studies showed the existence of cerebellar components in muscle atonia and phasic activities of the eyes' lateral rectus muscle during REM (Jouvet, 1962; Guglielmino and Strata, 1971; Gadea-Ciria and Fuentes, 1976; Cunchillos and De Andrés, 1982). Together with these actions, the cerebellum has important influences on intrinsic sleep mechanisms as was first indicated by the changes observed in cortical and thalamic electrical activity that follow electrical stimulation and lesion of different cerebellar structures.

Moruzzi (1958) reported that diffuse EEG effects could be obtained through the efferent of the nucleus dentatus, this effect was also obtained with low-frequency electrical stimulation of the nucleus fatigius, while high frequency stimulation of this nucleus produced diffuse EEG activation (Fadiga et al., 1968). Specific superficial thalamocortical responses (surface negativedeep positive potentials) in the frontal and parietal cortices were also produced by stimulation of the cerebellar nuclei (Sasaki et al., 1976). Suppression of the impulses from the deep cerebellar nuclei through lesion of the brachium conjunctivum tract produce, together with a bilateral activation of the EEG, the appearance of synchronized bursts of intermediate- to high-voltage EEG activity in the theta band $(7-13 \mathrm{~Hz}$, bigger of $250 \mathrm{mv})$ that can be recorded in frontal and parietal cortical areas that are targets of the projections from the thalamic nuclei that receive cerebellar afferents (Camacho-Evangelista and Reinoso-Suárez, 1965; ReinosoSuárez, 1992, 1993). The bioelectrical features of these synchronized bursts are similar to the relaxation rhythms described in cats during periods of relaxed wakefulness or drowsiness (Ursin and Sterman, 1981). A similar EEG synchronization, most conspicuously recorded in the ipsilateral frontal and parietal cortices, appears especially after the lesion of the brachium conjunctivum tract at the level of the red nucleus (Reinoso-Suárez, 1954). This intermediate- to high-voltage SWA in the theta band can also be recorded in the thalamic paralaminar nuclei that receive afferents from the cerebellum; it looks as if suppression of the cerebellar afferents releases these nuclei and allows them to fire at a possible intrinsic theta frequency, modulated by thalamic and other extrathalamic connections that, projecting to layer I, impose their bioelectrical activity on the frontal and parietal cortices (Figure 5; Reinoso-Suárez, 1992, 1993; Reinoso-Suárez et al., 2011). The two bioelectric phenomena after the lesion on the superior cerebellar peduncle (increased EEG activation and synchronized bursts of EEG activity in the theta band) are coherent with the SWC modifications after lesion of the superior cerebellar peduncle that significantly increase wakefulness and drowsiness while decreasing REM and NREM sleep (De Andrés and Reinoso-Suárez, 1979). The sleep suppression was a consequence of the decrease in both the duration and the number of the NREM episodes (Figure 8). Also, changes in sleep-wakefulness proportions occur after fastigial nuclei, cortical, or middle cerebellar peduncle lesions. All these studies point to an important participation by the cerebellum in SWC mechanisms through a functional antagonism in the regulation of the proportions of sleep and wakefulness between cerebellar cortex and deep cerebellar nuclei; that is, like the changes occurring after the brachium conjunctivum tract lesions, increased wakefulness, and decreased NREM and REM sleep were reported after bilateral lesions of the fastigial nuclei (Giannazzo et al., 1968). However, these effects were just the opposite after lesions in the middle cerebellar peduncle (Raffaele et al., 1971) or in the cortex of vermis and cerebellar hemispheres that produced increased NREM and REM sleep (De Andrés and Reinoso-Suárez, 1979; García-Uría et al., 1980). Cerebellectomized animals present all SWC states (Jouvet, 1962; Paz et al., 1982). However and surprisingly, in spite of the severe neurological deficits produced by cerebellectomy, the quantitative alterations in the proportions of SWC states in cerebellectomized animals are smaller than those produced by localized subcortical or cortical cerebellar lesions. In our experiments (Cunchillos and De Andrés, 1982) with cerebellectomized cats, the main change after cerebellectomy was an increase in drowsiness that persisted during the entire survival time ( 5 weeks) and that was associated with small decreases in both W and NREM sleep as well as an increase in REM sleep. These results confirm cerebellar involvement in mechanisms of synchronized EEG and support the hypothesis that the cerebellum, through dual opposite cortical and subcortical effects, would have an important regulatory action in the fine adjustments in the proportions of SWC states for maintaining the sleep-wakefulness equilibrium (Cunchillos and De Andrés, 1982).

A recent study (Dang-Vu et al., 2008) with functional magnetic resonance imaging has reported that the slow oscillation $<1 \mathrm{~Hz}$ rhythm of NREM sleep is associated with significantly increased local activity in specific cerebral regions: the parahippocampal gyrus and cerebellum (in both cerebellar hemispheres and vermis). On the basis of parallel changes that occur in forebrain and cerebellum during NREM sleep, Andre and Arrighi (2003) have proposed that forebrain and cerebellum may cooperate strongly in information processing during sleep. As yet no further studies have examined cerebellar participation at the cellular level in the generation of the slow $<1 \mathrm{~Hz}$ NREM sleep rhythm, but the Dang-Vu et al. (2008) findings may be indicative of parallel operating capabilities in the cerebellum and hippocampal formation during NREM sleep. The growing data on hippocampal activation during NREM sleep after memory task training (Peigneux et al., 2004; Ji and Wilson, 2007; Rasch et al., 2007) and recent compelling evidence that slow $<1 \mathrm{~Hz}$ oscillations have a causal role in consolidating memories during NREM sleep (Marshall et al., 2006) open the possibility of cerebellar-forebrain cooperation in memory consolidation processes during NREM sleep.

\section{NREM SLEEP HOMEOSTASIS}

The current dominant theory in sleep research considers that the connections between structures putatively responsible for each of the three phases of the SWC (wakefulness, REM, and NREM sleep) would provide the anatomical basis for the central organization of reciprocal interactions among these structures and result in the alternation of the different phases of the SWC under the circadian control of the suprachiasmatic nucleus (Reinoso-Suárez et al., 2001). In addition, we would note that, in humans and 


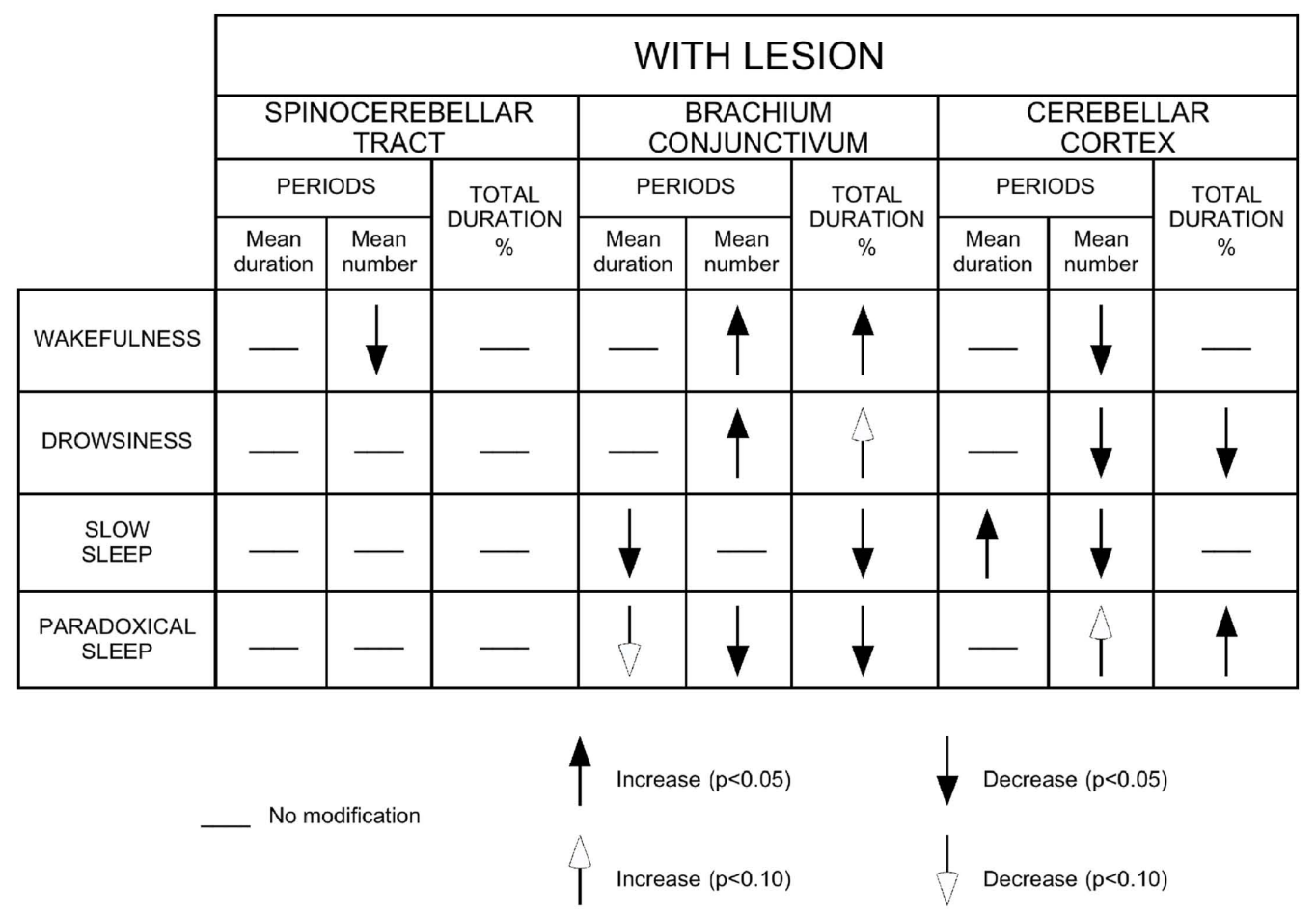

FIGURE 8 | Modifications in the total duration of wakefulness, drowsiness, NREM (slow sleep), and REM (paradoxical) sleep, as well as their episode mean duration and number per recording after different cerebellar lesions. The cats with lesions in the brachium conjunctivum showed a significant decrease of NREM
(Slow Wave) and REM (Paradoxical) sleep. In contrast, the cats with lesions in the cerebellar cortex and white matter of the anterior vermis showed a significant decrease of drowsiness and a significant increase in REM sleep. Modified from De Andrés and Reinoso-Suárez (1979).

Neuronal activity during wakefulness increases the synthesis of NREM sleep regulating molecules; this increase, as occurs with the effects of adenosine on the A1-receptor, leads to the inhibition of neuronal activity, thereby increasing sleep pressure, and finally NREM begins (Vassalli and Dijk, 2009). Although NREMpromoting substances act on basal forebrain and hypothalamic NREM sleep regulating circuits (Gvilia et al., 2006a,b), they can also act locally on the cerebral cortex and thalamus to change the electrical properties of thalamic and cortical neurons thus altering their input-output relationships (Krueger et al., 2008). These observations help explain the capacity of the isolated forebrain to exhibit NREM sleep rebound (Corpas and De Andrés, 1991).

Currently, NREM and REM sleep are considered behavioral states involving the whole organism and governed by central control mechanisms. Although accepting this point of view, there is increasing evidence that NREM sleep (and thus sleep) might be a fundamental property of local neuronal networks since it can be initiated at small brain assemblies in response to their use, and only later on be consolidated by general central mechanisms (Krueger et al., 2008; Rector et al., 2009). One of the smallest sleep units could be the individual cortical columns in which sensory stimulation produces fluctuating high and low amplitude evoked responses depending on the behavioral state. In sleeping animals, the sleep-like response in cortical columns is characterized by evoked response potentials with a greater amplitude that the evoked responses during wakefulness (Rector et al., 
2005). However, the sleep-/wake-like response also seems to be an intrinsic property of the individual cortical columns since, independently of the behavioral state of the whole-animal, the probability of finding a column in a sleep-like state depends on the length of time that column has previously spent in the wakelike state (Rector et al., 2005), suggesting that in different cortical regions cortical columns can be sleeping while others are awake during both whole-animal wakefulness and sleep. Thus, these findings suggest that NREM sleep may be regulated at local neuronal assembly levels and this regulation appears to be a fundamental property of the neural networks and it depends on prior activity in each network (Krueger et al., 2008). The NREM sleep of each local cortical column can be initiated by metabolically driven changes derived from the manufacture of molecules of sleep-regulatory substances produced by neuronal activity during wakefulness-like activity. The process may involve increased electrical activity, blood flow, extracellular levels of ATP and extra-and intracellular levels of adenosine, all of which would decrease the intracellular ATP level, and this would drive individual columns to enter a sleep-like activity state. Once a final sleep state was reached this process would be reversed: reduced electrical activity, blood flow, extracellular levels of ATP and extra-and intracellular levels of adenosine would raise the intracellular ATP level in individual local cortical columns, and thus, the cortical column would be prepared for wakefulness. The sleep or wakefulness states of individual cortical columns could be synchronized through humoral and electrical connections and therefore the sleep or wakefulness of the whole organism would occur as an emergent property of the interaction of individual networks (Krueger et al., 2008). Nowadays there is an emerging understanding of the role of astrocytes as potential mediators of the known effect of adenosine in sleep regulation and this mediation would involve both neuroenergetic and synaptic plasticity roles (Jones, 2009).

The power of delta SWA in the EEG is considered to be an indicator of NREM sleep intensity, and delta SWA is homeostatically regulated since its power increases after wakefulness and returns to baseline during sleep. The magnitude of delta SWA is the best known correlation of sleep homeostasis or "sleep pressure." Indeed, experiments have shown that the power of SWA reflects the duration of prior wakefulness regardless of the circadian time. Delta SWA seems to reflect a form of restorative process for cortical local circuits: SWA delta power is increased in cortical areas that have been most active during the day. Also, imaging techniques have shown that there is a localized decrease in metabolic activity at night in areas that have been activated during the day (Mignot and Huguenard, 2009). SWA homeostasis may reflect synaptic changes underlying a cellular need for sleep. Nevertheless, Huber et al. (2004) have indicated that sleep homeostasis has a local component, one that can be triggered in specific human brain regions by a learning task; these authors also showed that the local increase in SWA after learning correlates with improved performance of the task after sleep. Thus, sleep homeostasis can be induced on a local level and can improve performance.

As we have indicated above delta EEG waves are synchronized in the different cortical areas in correlation with the neuronal events that express cyclic potential membrane fluctuations $(<1 \mathrm{~Hz})$ between hyperpolarized (DOWN) and depolarized (UP) periods in which neurons are respectively silent or active (Dossi et al., 1992; Contreras and Steriade, 1995). More recently, Vyazovskiy et al. (2009) have shown that during NREM, barrel cortex multiunit activity expresses cyclic $(<1 \mathrm{~Hz})$ changes with silent periods $(\mathrm{OFF})$ alternating with others $(\mathrm{ON})$ in which there is a sustained firing activity; these ON/OFF cortical multiunit activities closely resemble the neuronal membrane potential events of UP/DOWN states. In addition, Vyazovskiy et al. (2009) also showed that the multiunit OFF periods in barrel cortical neurons are temporally correlated with the negative component of the EEG delta waves as are the DOWN states that occur at cellular level (Contreras and Steriade, 1995). During the first NREM sleep after an uninterrupted waking period, neuronal barrel cortex population ON periods are short and frequent, while neuronal silence periods (DOWN states) are long and frequent. DOWN states (accompanied by an overall decrease in neuronal activity) are a phenomenon that is thought to be associated with energy savings. After a sustained sleep period, which reduces the sleep debt, barrel cortex OFF periods decrease and the duration of the ON periods increases. In addition, the changes in firing patterns in NREM sleep correlate positively with changes in SWA intensity (Vyazovskiy et al., 2009). Therefore, the systematic increase of firing during wakefulness is balanced by staying asleep.

Recent data (Jones et al., 2008) indicate that sleep reduces the number of synaptic connections to a basic level that is augmented during waking experience that is, NREM sleep seems to ensure cell homeostasis; simultaneously during sleep the expression of molecules involved in synaptic reorganization is increased. Based on simple energy demands and since the cerebral cortex-thalamus unit is a large part of the human and mammal brain, being awake for longer and longer periods of time seems to be very expensive, hence energy economy by the brain during NREM sleep is one of the prevalent hypotheses to explain NREM sleep pressure (Mignot and Huguenard, 2009). However, during NREM sleep neurons must down-fire in synchrony rather than simply stay silent; for some authors this circumstance supports the need to transfer memory to different cortical areas, as has been demonstrated to occur between the hippocampus and visual cortex. To Vyazovskiy et al. (2009), wakefulness is associated with learning, and enhancing long-term potentiation strengthens glutamatergic synapses, a process with an unsustainable energy requirement, whereas during sleep only robust connections remain intact, reducing the energy requirements to the levels necessary for maintaining critical learned circuits. This reduction of synapses during sleep increases the signal to noise ratio for the remaining connections, improving performance (Mignot and Huguenard, 2009; Vyazovskiy et al., 2009).

The close reciprocal connections between the thalamus and the cerebral cortex would force NREM sleep homeostatic processes to take place simultaneously in the two structures. The thalamuscerebral cortex is a strictly necessary unit in the expression of the most significant bioelectric and behavioral events of NREM sleep and the thalamus-cerebral cortex unit is connected to subcortical NREM sleep-promoting structures and with all the subcortical structures involved in the organization of the other phases of SWC (Reinoso-Suárez et al., 2011). 
The former connections would act on the thalamus-cerebral cortex unit to facilitate the NREM sleep neurophysiological and homeostatic processes and also through neurophysiological and homeostatic mechanisms, the latter subcortical connections would inhibit the other phases of SWC: REM sleep and wakefulness.

\section{REFERENCES}

Alam, M. N., McGinty, D., and Szymusiak, R. (1995). Neuronal discharge of preoptic/anterior hypothalamic thermosensitive neurons: relation to NREM sleep. Am. J. Physiol. 269, R1240-R1249.

Amzica, F., and Steriade, M. (1995). Disconnection of intracortical synaptic linkages disrupts synchronizatrion of a slow oscillation. J. Neurosci. 15, 4658-4677.

Andrade, K. C., Spoormaker, V. I., Dresler, M., Wehrle, R., Holsboer, F., Sämann, P. G., and Czisch, M. (2011). Sleep spindles and hippocampal functional connectivity in human NREM sleep. J. Neurosci. 31, 10331-10339.

Andre, P., and Arrighi, P. (2003). Hipnic modulation of cerebellar information processing: implications for the cerebro-cerebellar dialogue. Cerebellum 2, 84-95.

Avendaño, C., Stepniewska, I., Rausell, E., and Reinoso-Suárez, F. (1990). Segregation and heterogeneity of thalamic cell populations projecting to superficial layers of the posterior parietal cortex: a retrograde tracing study in the cat and monkey. Neuroscience 39, 547-559.

Bal, T., and McCormick, D. A. (1993). Mechanisms of oscillatory activity in guinea-pig nucleus reticularis thalami in vitro: a mammalian pacemaker. J. Physiol. (Lond.) 468, 669-691.

Batini, C., Moruzzi, G., Palestini, M., Rossi, G. F., and Zanchetti, A. (1958). Persistent patterns of wakefulness in the pretrigeminal midpontine preparation. Science 128, 30-32.

Berlucchi, G., Maffei, L., Moruzzi, G., and Strata, P. (1964). EEG and behavioral effects elicited by cooling of medulla and pons. Arch. Ital. Biol. 102, 372-392.

Bonjean, M., Baker, T., Lemieux, M., Timofeev, I., Sejnowski, T., and Bazhenov, M. (2011). Corticothalamic feedback controls sleep spindle duration in vivo. J. Neurosci. 31, 9124-9134.

Camacho-Evangelista, A., and ReinosoSuárez, F. (1964). Activating and synchronizing centers in cat brain: electroencephalograms after lesions. Science 146, 268-270.
Camacho-Evangelista, A., and ReinosoSuárez, F. (1965). "Effects on the EEG of lesions in the tractus brachium conjunctivum," in 6th International Congress Electroencephalography Clinical Neurophysiology, Vienna, 467-470.

Chou, T. C., Bjorkum, A. A., Gaus, S. E. Lu, J., Scammell, T. E., and Saper, C. B. (2002). Afferents to the ventrolateral preoptic nucleus. J. Neurosci. 22, 977-990.

Cirelli, C. (2009). The genetic and molecular regulation of sleep: from fruit flies to humans. Nat. Rev. Neurosci. 10, 549-560.

Cirelli, C., and Tononi, G. (2008). Is sleep essential? PLoS Biol. 6, e216. doi:10.1371/journal.pbio.0060216

Contreras, D., and Steriade, M. (1995). Cellular basis of EEG slow rhythms: a study of dynamic corticothalamic relationships. J. Neurosci. 15, 604-622.

Cordeau, J. P., and Mancia, M. (1959). Evidence for the existence of an electroencephalographic synchronization mechanism originating in the lower brain stem. Electroencephalogr. Clin. Neurophysiol. 3, 551-564.

Corpas, I., and De Andrés, I. (1991). Morphine effects in brainstem transected cats: I. EEG and sleepwakefulness in the isolated forebrain. Behav. Brain Res. 44, 11-19.

Cunchillos, J. D., and De Andrés, I. (1982). Participation of the cerebellum in the regulation of the sleep-wakefulness cycle. Results in cephalogr. Clin. Neurophysiol. 53, 549-558.

Dang-Vu, T. T., Schabus, M., Desseilles, M., Albouy, G., Boly, M., Darsaud, A., Gais, S., Rauchs, G., Sterpenich, V., Vandewalle, G., Carrier, J., Moonen, G., Balteau, E., Degueldre, C., Luxen, A., Phillips, C., and Maquet, P. (2008). Spontaneous neural activity during human slow wave sleep. Proc. Natl. Acad. Sci. U.S.A. 105, 15160-15165.

Datta, S., and MacLean, R. R. (2007). Neurobiological mechanisms for the regulation of mammalian sleepwake behavior: reinterpretation of historical evidence and inclusion of contemporary cellular and molecular evidence. Neurosci. Biobehav. Rev. 31, 775-824. cerebellectomized cats. Electroen-

\section{ACKNOWLEDGMENTS}

Grant BFU2009-06991/BFI from the Spanish Ministry of Science and Innovation supported this work. We acknowledge very valuable suggestions from Dr. C. de la Roza on the NREM sleep homeostasis section. We thank Ms. M. Callejo for technical assistance and Ms. C. F. Warren for revision of English language usage.

De Andrés, I., and Corpas, I. (1991). Morphine effects in brainstemtransected cats: II. Behavior and sleep of the decerebrate cat. Behav. Brain Res. 44, 21-26.

De Andrés, I., Garzón, M., and Villablanca, J. R. (2003). The disconnected brain stem does not support rapid eye movement sleep rebound following selective deprivation. Sleep 26, 419-425.

De Andrés, I., Gutiérrez-Rivas, E. Nava, E., and Reinoso-Suárez, F. (1976). Independence of sleepwakefulness cycle in an implanted head 'encephale isole.' Neurosci. Lett. 2, 13-18.

De Andrés, I., and Reinoso-Suárez, F. (1979). Participation of the cerebellum in the regulation of the sleepwakefulness cycle through the superior cerebellar peduncle. Arch. Ital. Biol. 117, 140-163.

Dossi, R. C., Nuñez, A., and Steriade, M. (1992). Electrophysiology of a slow (0.5-4 Hz) intrinsic oscillation of cat thalamocortical neurones in vivo. $J$. Physiol. 447, 215-434.

Eguchi, K., and Satoh, T. (1980). Convergence of sleep-wakefulness subsystems onto single neurons in the region of cat's solitary tract nucleus. Arch. Ital. Biol. 118, 331-345.

Fadiga, E., Manzoni, T., Sapienza, S., and Urbano, A. (1968). Synchronizing and desynchronizing fastigial influences on the electrocortical activity of the cat, in acute experiments. Electroencephalogr. Clin. Neurophysiol. 24, 330-342.

Fuentealba, P., and Steriade, M. (2005). The reticular nucleus revisited: intrinsic and network properties of a thalamic pacemaker. Prog. Neurobiol. 75, 125-141.

Gadea-Ciria, M., and Fuentes, J. (1976). Analysis of phasic activities in the lateral rectus muscle of the eyes (PALRE) during paradoxical sleep in chronic cerebellectomized cats. Brain Res. 111, 416-415.

Gallopin, T., Fort, P., Eggermann, E., Cauli, B., Luppi, P. H., Rossier, J., Audinat, E., Mühlethaler, M., and Serafin, M. (2000). Identification of sleep-promoting neurons in vitro. Nature 404, 992-995.

García-Uría, J., De Andrés, I., Cunchillos, J. D., and Reinoso-Suárez, F. (1980). "Modification of the sleep-wakefulness cycle after surgical removal of the cerebellar cortex," in Sleep 1978, eds L. Popoviciu, B. Asgian, and G. Badiu (Basel: Karger Medical and Scientific Publishers), 289-292.

Garzón, M. (1996). Estudio morfofuncional de los núcleos reticular oral y reticular caudal del tegmento pontino como regiones generadoras de sueño paradójico. Doctoral Thesis, Universidad Autónoma de Madrid, Madrid.

Giannazzo, E., Manzoni, T., Raffaele, R., Sapienza, S., and Urbano, A. (1968). Changes in the sleep-wakefulness cycle induced by chronic fastigial lesions in the cat. Brain Res. 11, 281-284.

Golanov, E. V., and Reis, D. J. (2001). Neurons of nucleus of the solitary tract synchronize the EEG and elevate cerebral blood flow via a novel medullary area. Brain Res. 892, 1-12.

Gong, H., McGinty, D., Guzman-Marin, R., Chew, K. T., Stewart, D., and Szymusiak, R. (2004). Activation of c-fos in GABAergic neurones in the preoptic area during sleep and in response to sleep deprivation. $J$. Physiol. 556, 935-946.

Gottesmann, C. (1996). The transition from slow-wave sleep to paradoxical sleep: evolving facts and concepts of the neurophysiological processes underlying the intermediate stage of sleep. Neurosci. Biobehav. Rev. 20, 367-387.

Guglielmino, S., and Strata, P. (1971). Cerebellum and atonia of the desynchronized phase of sleep. Arch. Ital. Biol. 109, 210-217.

Guzmán-Marín, R., Alam, M. N., Szymusiak, R., Drucker-Colín, R., Gong, H., and McGinty, D. (2000). Discharge modulation of rat dorsal raphe neurons during sleep and waking: effects of preoptic/basal forebrain warming. Brain Res. 875, 23-34.

Gvilia, I., Turner, A., McGinty, D., and Szymusiak, R. (2006a). Preoptic area neurons and the homeostatic regulation of rapid eye movement sleep. J. Neurosci. 26, 3037-3044.

Gvilia, I., Xu, F., McGinty, D., and Szymusiak, R. (2006b). Homeostatic regulation of sleep: a role for preoptic area neurons. J. Neurosci. 26, 9426-9433. 
Hernández-Peón, R. (1962). Sleep induced by localized electrical or chemical stimulation of the forebrain. Electroencephalogr. Clin. Neurophysiol. 14, 423-424.

Hess, W. R. (1931). Le sommeil. C. R. Soc. Biol. Paris 107, 1333-1360.

Hess, W. R. (1968). Psychologie in biologisher Sicht, 2 Aufl. Stuttgart: G. Thieme.

Hodes, R. (1964). Electrocortical desynchronization resulting from spinal block: evidence for synchronizing influences in the cervical cord. Arch. Ital. Biol. 102, 183-196.

Huber, R., Ghilardi, M. F., Massimini, M., and Tononi, G. (2004). Local sleep and learning. Nature 430, 78-81.

Iber, C., Ancoli-Israel, S., Chesson, A., Quan, S. F. (eds). (2007). "The AASM manual for the scoring of sleep and associated events: rules, terminology, and technical specification," 1st Edn. Westchester, IL: American Academy of Sleep Medicine.

Jahnsen, H., and Llinás, R. (1984). Electrophysiological properties of guinea-pig thalamic neurons: and in vitro study. J. Physiol. (Lond.) 349, 205-226.

Ji, D., and Wilson, M. A. (2007). Coordinated memory replay in the visual cortex and hippocampus during sleep. Nat. Neurosci. 10, 100-107.

Jiménez-Castellanos, J., and ReinosoSuárez, F. (1985). Topographical organization of the afferent connections of the principal ventro-medial thalamic nucleus in the cat. J. Comp. Neurol. 236, 297-314.

Jones, B. E. (2009). Glia, adenosine, and sleep. Neuron 61, 156-157.

Jones, E. G. (2001). The thalamic matrix and thalamocortical synchrony. Trends Neurosci. 24, 595-601.

Jones, S., Pfister-Genskow, M., Benca, R. M., and Cirelli, C. (2008). Molecular correlates of sleep and wakefulness in the brain of the whitecrowned sparrow. J. Neurochem. 105, 46-62.

Jouvet, M. (1962). Research on the neural structures and responsible mechanisms in different phases of physiological sleep. Arch. Ital. Biol. 100, 125-206.

Krilowicz, B. L., Szymusiak, R., and McGinty, D. (1994). Regulation of posterior lateral hypothalamic arousal related neuronal discharge by preoptic anterior hypothalamic warming. Brain Res. 668, 30-38.

Krueger, J. M., Rector, D. M., Roy, S., Van Dongen, H. P., Belenky, B., and Panksepp, J. (2008). Sleep as a fundamental property of neuronal assemblies. Nat. Rev. Neurosci. 9, 910-919.
Laguzzi, R., Reis, D. J., and Talman, W. T. (1984). Modulation of cardiovascular and electrocortical activity through serotonergic mechanisms in the nucleus tractus solitarius of the rat. Brain Res. 304, 321-328.

Llinás, R., and Steriade, M. (2006). Bursting of thalamic neurons and states of vigilance. J. Neurophysiol. 95, 3297-3308.

Madoz, P., and Reinoso-Suárez, F. (1968). Influence of lesions in preoptic region on the states of sleep and wakefulness. Proc. XXIV Int. Cong. Physiol. Sci. 7, 276.

Magnes, J., Moruzzi, G., and Pompeiano, O. (1961). Synchronization of the EEG produced by lowfrequency electrical stimulation of the region of the solitary tract. Arch. Ital. Biol. 99, 33-67.

Mancia, M., Meulders, M., and Santibanez, H. G. (1959). Synchronisation de l'électroencéphalogramme provoquée par la stimulation visuelle répétitive chez le chat “médiopontin prétrigéminal.” Arch. Int. Physiol. Biochem. 67, 661-670.

Marshall, L., Helgadóttir, H., Mölle, M., and Born, J. (2006). Boosting slow oscillations during sleep potentiates memory. Nature 444, 610-613.

McGinty, D., and Szymusiak, R. (2000). The sleep-wake switch: a neuronal alarm clock. Nat. Med. 6, 510-511.

McGinty, D. J., and Sterman, M. B. (1968). Sleep suppression after basal forebrain lesions in the cat. Science 160, 1253-1255.

Mignot, E., and Huguenard, J. R. (2009). Resting our cortices by going DOWN to sleep. Neuron 63, 719-721.

Moreno-Balandrán, E., Garzón, M., Bódalo, C., Reinoso-Suárez, F., and De Andrés, I. (2008). Sleepwakefulness effects after microinjections of hypocretin 1 (orexin A) in cholinoceptive areas of the cat oral pontine tegmentum. Eur. J. Neurosci. 28, 331-341.

Morrison, R. S., and Dempsey, E. W. (1942). A study of thalamocortical relations. Am. J. Physiol. 135, 282-302.

Moruzzi, G. (1958). "Relations between the cerebellum and other central structures. Effects on the electrocorticogram," in The Physiology and Pathology of the Cerebellum, eds H. R. Dow and G. Moruzzi (Minneapolis: The University of Minnesota Press), 323-333.

Moruzzi, G. (1972). The sleep-waking cycle. Ergeb. Physiol. 64, 1-165.

Nauta, W. J. H. (1946). Hypothalamic regulation of sleep in rats. An experimental study. J. Neurophysiol. 9, 285-316.
Nuñez, A., Curró Dossi, R., Contreras, D., and Steriade, M. (1992). Intracellular evidence for incompatibility between spindle and delta oscillations in thalamocortical neurons of cat. Neuroscience 48, 75-85.

Núñez-Molina, A., and Amzica, F (2004). Mecanismos de generación de las oscilaciones lentas del electroencefalograma durante el sueño. Rev. Neurol. 39, 628-633.

Oka, H., Ito, J., and Kawamura, M. (1982). Identification of thalamocortical neurons responsible for cortical recruiting and spindling activities in cats. Neurosci. Lett. 33, 13-18.

Paz, C., Reygadas, E., and FernándezGuardiola, A. (1982). Sleep alterations following total cerebellectomy in cats. Sleep 5, 218-226.

Peigneux, P., Laureys, S., Fuchs, S., Collette, F., Perrin, F., Reggers, J., Phillips, C., Degueldre, C., Del Fiore, G., Aerts, J., Luxen, A., and Maquet, P. (2004). Are spatial memories strengthened in the human hippocampus during slow wave sleep? Neuron 44, 535-545.

Pompeiano, O., and Swett, J. E. (1962). EEG behavioural manifestation of sleep induced by cutaneous nerve stimulation in normal cats. Arch. Ital. Biol. 100, 311-342.

Puizillout, J. J., Ternaux, J. P., Foutz, A. S. and Dell, P. (1973). Slow wave sleep with phasic discharges. Triggering by vago-aortic stimulation. Rev. Electroencephalogr. Neurophysiol. Clin. 3, 21-37.

Raffaele, R., Sapienza, S., Urbano, A., and Ventura, M. (1971). Changes in the sleep-wakefulness rhythm after chronic bilateral interruption of the middle cerebellar peduncles in the cat. Brain Res. 26, 195-199.

Rai, S., Kumar, S., Alam, M. A., Szymusiak, R., McGinty, D., and Alam, M. N. (2010). Al receptor mediated adenosinergic regulation of perifornical-lateral hypothalamic area neurons in freely behaving rat. Neuroscience 167, 40-48.

Rasch, B., Büchel, C., Gais, S., and Born, J. (2007). Odor cues during slow-wave sleep prompt declarative memory consolidation. Science 315 , 1426-1429.

Rector, D. M., Schei, J. L., Van Dongen, H. P., Belenky, G., and Krueger, J. M. (2009). Physiological markers of local sleep. Eur. J. Neurosci. 29, 1771-1778.

Rector, D. M., Topchiy, I. A., Carter, K. M., and Rojas, M. J. (2005). Local functional state differences between rat cortical columns. Brain Res. 1047, 45-55.

Reinoso-Barbero, F. (1993). Microestimulación con opiaceos en la region del tracto solitario. Efectos sobre el ciclo vigilia-sueño e interacción con efectos vegetativos. Doctoral Thesis, Universidad Autónoma de Madrid, Madrid.

Reinoso-Barbero, F., and De Andrés, I. (1995). Effects of opioid microinjections in the nucleus of the solitary tract on the sleep-wakefulness cycle states in cats. Anesthesiology 82, 144-152.

Reinoso-Suárez, F. (1954). Die Auswirkungen der Ausschaltung eines Nucleus ruber auf die Hirnrinde (Electroencephalographische Untersuchungen an der Katze). Dtsch. Z. Nervenheilk 172, 201-219.

Reinoso-Suárez, F. (1961). Topographischer Hirnatlas der Katze für Experimental Physiologische Untersuchungen. Darmstadt: Merck AG.

Reinoso-Suárez, F. (1992). "Considerations on thalamic and pontine sleep mechanisms," in Fundamental Neurobiology, ed. R. Velluti (Montevideo: Work), 59-71.

Reinoso-Suárez, F. (1993). Algunas consideraciones sobre la anatomía del sueño. An. Anat. 39, 165-181.

Reinoso-Suárez, F., and De Andrés, I. (1976). Brain structures and sleep. Trab. Inst. Cajal Invest. Biol. 68, 39-68.

Reinoso-Suárez, F., De Andrés, I., and Garzón, M. (2011). Functional anatomy of the sleep-wakefulness cycle: wakefulness. Adv. Anat. Embryol. Cell. Biol. 208, 1-128.

Reinoso-Suárez, F., De Andrés, I., Rodrigo-Angulo, M. L., and Garzón, M. (2001). Brain structures and mechanisms involved in the generation of REM sleep. Sleep Med. Rev. 5, 63-78.

Reinoso-Suárez, F., de la Roza, C., Rodrigo-Angulo, M. L., de Andrés, I., Núñez, A., and Garzón, M. (2010). "GABAergic mechanisms in the ventral oral pontine tegmentum - the REM sleep induction site- in the modulation of sleep-wake states," in GABA and Sleep, ed. J. M. Monti, S. R. Pandi-Perumal, and H. Möhler (Basel: Birkhauser-Verlag), 233-252.

Reinoso-Suárez, F., Fairén, A., MartínezMoreno, E., Nava, B. E., and Pasquier, D. A. (1977). Ascending projections from the brain stem. Med. Biol. Pap. 1, 233-246.

Reinoso-Suárez, F., Sierra, G., and Camacho, A. (1962). Efectos de lesiones en formación reticular protuberancial e istmo pontomesencefálico sobre el EEG del gato (Su participación en el mecanismo del sueño). Rev. Med. Univ. Navarra 6, 1-19. 
Rossi, G. F., Minobe, K., and Candia, O. (1963). An experimental study of the hypnogenic mechanisms of the brain stem. Arch. Ital. Biol. 101, 470-492.

Rubio-Garrido, P., Pérez-de-Manzo, F., Porrero, C., Galazo, M. J., and Clascá, F. (2009). Thalamic input to distal apical dendrites in neocortical layer 1 is massive and highly convergent. Cereb. Cortex 19, 2380-2395.

Saper, C. B. (1995). "Central autonomic system," in The Rat Nervous System, ed. G. Paxinos (San Diego: Academic Press), 107-135.

Saper, C. B., Chou, T. C., and Scammell, T. E. (2001). The sleep switch: hypothalamic control of sleep and wakefulness. Trends Neurosci. 24, 726-731.

Sasaki, K., Kawaguchi, S., Oka, H., Sakai, M., and Mizuno, N. (1976). Electrophysiological studies on the cerebello cerebral projections in monkeys. Exp. Brain Res. 24, 495-507.

Sforza, E., Montagna, P., Tinuper, P., Cortelli, P., Avoni, P., Ferrillo, F., Petersen, R., Gambetti, P., and Lugaresi, E. (1995). Sleep-wake cycle abnormalities in fatal familial insomnia. Evidence of the role of the thalamus in sleep regulation. Electroencephalogr. Clin. Neurophysiol. 94, 398-405.

Sherin, J. E., Elmquist, J. K., Torrealba, F., and Saper, C. B. (1998). Innervation of histaminergic tuberomammillary neurons by GABAergic and galaninergic neurons in the ventrolateral preoptic nucleus of the rat. J. Neurosci. 18, 4705-4721.

Sherin, J. E., Shiromani, P. J., McCarley, R. W., and Saper, C. B. (1996). Activation of ventrolateral preoptic neurons during sleep. Science 271, 216-219.

Siegel, J. M., Tomaszewsky, K. S., and Nienhuis, R. (1986). Behavioral states in the chronic medullary and midpontine cat. Electroencephalogr. Clin. Neurophysiol. 63, 274-288.

Starzl, T. E., and Magoun, H. W. (1951). Organization of the diffuse thalamic projection system. J. Neurophysiol. 14, 133-146.

Steininger, T. L., Gong, H., McGinty, D., and Szymusiak, R. (2001). Subregional organization of preoptic area/anterior hypothalamic projections to arousal-related monoaminergic cell groups. J. Comp. Neurol. 429, 638-653.

Steriade, M., and Deschenes, M. (1988). "Intrathalamic and brainstemthalamic networks envolved in resting and alert status," in Cellular Thalamic Mechanisms, eds M. Bentivoglio and R. Spreafico (New Cork: Elsevier), 37-62.

Steriade, M., Deschênes, M., Domich, L., and Mulle, C. (1985). Abolition of spindle oscillations in thalamic neurons disconnected from nucleus reticularis thalami. J. Neurophysiol. 54, 1473-1497.

Steriade, M., Dossi, R. C., and Nuñez, A. (1991). Network modulation of a slow intrinsic oscillation of cat thalamocortical neurons implicated in sleep delta waves: cortically induced synchronization and brainstem cholinergic suppression. J. Neurosci. 10, 3200-3217.

Steriade, M., and McCarley, R. W. (1990). Brainstem Control of Wakefulness and Sleep. New York: Plenum. Steriade, M., Nuñez, A., and Amzica, F. (1993). Intracellular analysis of relations between the slow (< $1 \mathrm{~Hz}$ ) neocortical oscillation and other sleep rhythms of the electroencephalogram. J. Neurosci. 13, 3266-3283.

Steriade, M., Oakson, G., and Ropert, N. (1982). Firing rates and patterns of midbrain reticular neurons during steady and transitional states of the sleep-waking cycle. Exp. Brain Res. $46,37-51$.

Sterman, M. B., and Clemente, C. D. (1962). Forebrain inhibitory mechanisms: sleep patterns induced by basal forebrain stimulation in the behaving cat. Exp. Neurol. 6, 103-117.

Szymusiak, R., Alam, N., Steininger, T. L., and McGinty, D. (1998). Sleepwaking discharge patterns of ventrolateral preoptic/anterior hypothalamic neurons in rats. Brain Res. 803, 178-188.

Szymusiak, R., Gvilia, I., and McGinty, D. (2007). Hypothalamic control of sleep. Sleep Med. 8, 291-301.

Szymusiak, R., and McGinty, D. (1986). Sleep suppression following kainic acid-induced lesions of the basal forebrain. Exp. Neurol. 94, 598-614.

Timofeev, I., and Steriade, M. (1996). Low-frequency rhythms in the thalamus of intact-cortex and decorticated cats. J. Neurophysiol. 76, 4152-4168.

Ursin, R., and Sterman, M. B. (1981). A Manual for Standardized Scoring of Sleep and Waking States in the Adult Cat. Los Angeles: University of California Brain Information Service.

Uschakov, A., Gong, H., McGinty, D. and Szymusiak, R. (2006). Sleepactive neurons in the preoptic area project to the hypothalamic paraventricular nucleus and perifornical lateral hypothalamus. Eur. J. Neurosci. 23, 3284-3296.

Valdés-Cruz, A., Magdaleno-Madrigal, V. M., Martínez-Vargas, D., Fernández-Mas, R., and AlmazánAlvarado, S. (2008). Long-term changes in sleep and electroencephalographic activity by chronic vagus nerve stimulation in cats. Prog. Neuropsychopharmacol. Biol. Psychiatry 32, 828-834.

Vassalli, A., and Dijk, D.-J. (2009). Sleep function: current questions and new approaches. Eur. J. Neurosci. 29, 1830-1841.

Velayos, J. L., Jiménez-Castellanos, J. Jr., and Reinoso-Suárez, F. (1989). Topographical organization of the projections from the reticular thalamic nucleus to the intralaminar and medial thalamic nuclei in the cat. J. Comp. Neurol. 279, 457-469.

Villablanca, J. R. (1965). The electrocorticogram in the chronic "cerveau isolé" of the cat. Electroencephalogr. Clin. Neurophysiol. 19, 576-586.

Villablanca, J. R. (1966). Behavioral and polygraphic study of "sleep" and "wakefulness" in chronic decerebrate cats. Electroencephalogr. Clin. Neurophysiol. 21, 562-577.

Villablanca, J. R. (1972). Permanent reduction in sleep after removal of cerebral cortex and striatum in cats. Brain Res. 36, 463-468.

Villablanca, J. R. (1974). "Role of the thalamus in sleep control: sleepwakefulness studies in chronic diencephalic and athalamic cats," in Basic Sleep Mechanisms, eds O. PetreQuadens and J. Schlag (New York: Academic), 51-81.

Villablanca, J. R. (2004). Counterpointing the functional role of the forebrain and of the brainstem in the control of the sleep-waking system. J. Sleep Res. 13, 179-208.

Viñes-Morros, R. (1959). Vias trigeminales y actividad bioeléctrica cerebral. An. Anat. 10, 507-527.

von Economo, C. (1930). Sleep as a problem of localization. J. Nerv. Ment. Dis. 71, 249-259.

Vyazovskiy, V. V., Olcese, U., Lazimy, Y. M., Faraguna, U., Esser, S. K., Williams, J. C., Cirelli, C., and Tononi, G. (2009). Cortical firing and sleep homeostasis. Neuron 63, 865-878.

Yang, Q. Z., and Hatton, G. I. (1997). Electrophysiology of excitatory and inhibitory afferents to rat histaminergic tuberomammillary nucleus neurons from hypothalamic and forebrain sites. Brain Res. 773, 162-172.

Yoshida, K., McCormack, S., España, R. A., Crocker, A., and Scammell, T. E. (2006). Afferents to the orexin neurons of the rat brain. J. Comp. Neurol. 494, 845-861.

Zarranz, J., and Reinoso-Suárez, F. (1971). The pontine tegmentum and sleep-wakefulness states. XXV Internat. Cong. Physiol. Sci. Munich, 618.

Conflict of Interest Statement: The authors declare that the research was conducted in the absence of any commercial or financial relationships that could be construed as a potential conflict of interest.

Received: 27 July 2011; paper pending published: 17 August 2011; accepted: 26 October 2011; published online: 15 November 2011.

Citation: de Andrés I, Garzón M and Reinoso-Suárez F (2011) Functional anatomy of non-REM sleep. Front. Neur. 2:70. doi: 10.3389/fneur.2011.00070 This article was submitted to Frontiers in Sleep and Chronobiology, a specialty of Frontiers in Neurology.

Copyright (ㄷ) 2011 de Andrés, Garzón and Reinoso-Suárez. This is an open-access article subject to a non-exclusive license between the authors and Frontiers Media $S A$, which permits use, distribution and reproduction in other forums, provided the original authors and source are credited and other Frontiers conditions are complied with. 